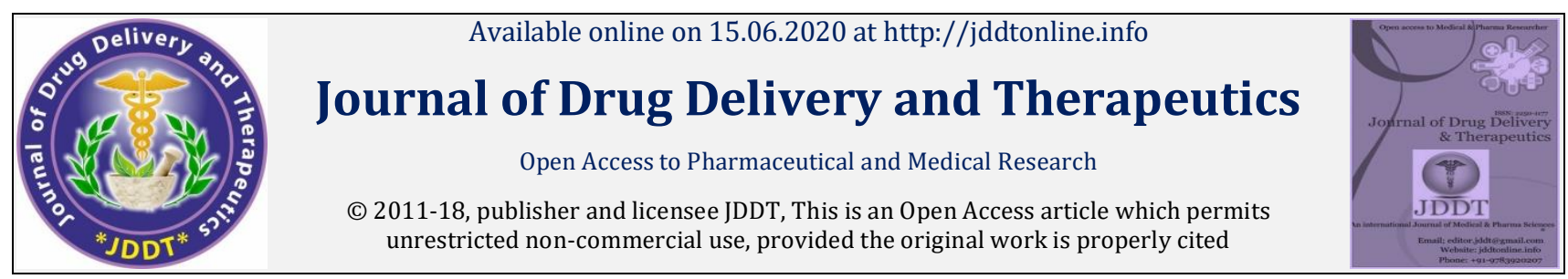

Open $\odot$ Access

Research Article

\title{
Isolation and Structure Elucidation of Quercetin like Structure from Dalbergia sissoo (Fabaceae)
}

\author{
${ }^{1}$ Research Scholar, Institute of Pharmacy, Bundelkhand University, Jhansi, Uttar Pradesh, India \\ 2 BIU College of Pharmacy, Bareilly International University, Bareilly, Uttar Pradesh, India \\ ${ }^{3}$ Keshlata College of Pharmacy, Bareilly International University, Bareilly, Uttar Pradesh, India \\ ${ }^{4}$ Department of Pharmaceutics, RSS College of Pharmacy, Baldeo, Mathura, Uttar Pradesh, India
}

Rohit Kumar Bijauliya ${ }^{* 1,2}$, Pushpendra Kannojia ${ }^{2}$, Pankaj Mishra ${ }^{3}$ and Gaurav Kumar Pathak

\begin{abstract}
The present study was conducted to isolate and classify Dalbergia sissoo (L.) bioactive compounds. The genus consists of 300 species in India, including 25 species. The generic name Dalbergia honors the $18^{\text {th }}$ century Swedish brothers Nils and Carl Dalberg. Various phytoconstituents of alkaloids, glycosides, flavanoids, tannins, saponins, sterols and terpenoids were isolated and classified from different parts of the plant. Thin Layer Chromatography, High Performance Thin Layer Chromatography, and Column Chromatography were used to isolate spots from the fraction of the crude extract to elucidate the chemical structure of Dalbergia sissoo (L.) leaf extract. Potential spots have been exposed to techniques of FTIR, NMR and mass spectroscopy. Column chromatography was exposed to the raw extract, obtaining 125 fractions, conducting TLC. Among them was a single band in TLC, characterized by FTIR, NMR spectroscopy and mass spectroscopy, and the structure was known as Quercetin. The results of this study indicate the effective potential compound of the ethanolic fraction of Dalbergia sissoo (L.).
\end{abstract}

Keywords: Dalbergia sissoo; Isolation \& Structure Elucidation; FTIR; NMR spectroscopy; Mass spectroscopy.

Article Info: Received 24 March 2020; Review Completed 19 May 2020; Accepted 24 May 2020; Available online 15 June 2020

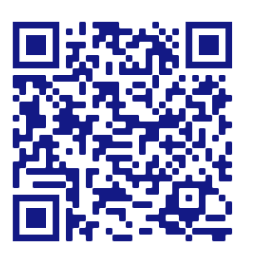

Cite this article as:

Bijauliya RK, Kannojia P, Mishra P and Pathak GK, Isolation and Structure Elucidation of Quercetin like Structure from Dalbergia sissoo (Fabaceae), Journal of Drug Delivery and Therapeutics. 2020; 10(3-s):6-11 http://dx.doi.org/10.22270/jddt.v10i3-s.4131

Mr. Rohit Kumar Bijauliya, Assistant Professor, Bareilly International University, College of Pharmacy, Bareilly, Uttar Prade sh, India

\section{INTRODUCTION:}

Herbal medicines have been universally accepted over the past few decades and have an impact on both global health and international trade. Medicinal plants therefore play an important role in a large number of the world's population's health care system. The key source of new pharmaceuticals and medical products is medicinal plants. Extraction and characterization from these green factories of several active phyto-compounds has given birth to some high activity profile products $\mathbf{1 , 2}$.

Dalbergia sissoo found on the banks of irrigation canals, it belongs to the Leguminoseae plant family, which is native to India and was long cultivated in Egypt ${ }^{3}$. Dalbergia sissoo is the Punjab State Tree (India) and the Punjab Provincial Tree (Pakistan). It is found to grow below 900 meters $(3,000 \mathrm{ft})$ elevation along banks of the river, but it can naturally reach up to $1,300 \mathrm{~m}(4,300 \mathrm{ft})$. It can withstand an average annual rainfall of up to 2,000 $\mathrm{mm}$ and 3-4 month droughts. It prefers pure sand and gravel soils to river banks ' rich alluvium. In slightly saline soils, Shisham can grow. Seedlings are shade intolerant. 4

Studies of pharmacognostic and phytochemical action on Dalbergia sissoo L. leaves have promoted us to undertake the present study. (Table 1). 
Table 1: Ethnomedical Information of Dalbergia sissoo Linn.

\begin{tabular}{|c|c|c|}
\hline Form used & Pharmacological activity & Reference \\
\hline Extract of aerial part & $\begin{array}{c}\text { Showed bronchodilation as well as significant antipyretic, } \\
\text { analgesic and estrogen like activities }\end{array}$ & 5 \\
\hline Dried leaves & Antibacterial, antiprotozoal and anti-inflammatory activity & 6 \\
\hline Leaf Juice & Used in gonorrhoea & 7 \\
\hline Wood paste & Used in Wound, Itches, Abscess and Vomiting & 7 \\
\hline Oil & $\begin{array}{l}\text { Shows repellent activity against Anopheles stephensi, Aedes } \\
\text { aegypti, Culex quinquefasciatus and is also resistant to some } \\
\text { wood boring insects }\end{array}$ & $8,9,10$ \\
\hline \multirow[t]{2}{*}{$\begin{array}{l}\text { Wood and active extract } \\
\text { of bark }\end{array}$} & $\begin{array}{l}\text { Ayurvedics: abortifacient, anthelmintic, antipyretic, aperitif, } \\
\text { aphrodisiac, expectorant, refrigerant, anal disorders, dysentery, } \\
\text { dyspepsia, leucoderma and skin ailments, }\end{array}$ & 7 \\
\hline & $\begin{array}{l}\text { Yunani: wood useful for blood disorders, } \\
\text { and nose disorders, burning sensations, scalding urine, stomach } \\
\text { problems, syphilis boils, eruptions, leprosy and nausea. }\end{array}$ & 8 \\
\hline
\end{tabular}

\section{MATERIALS AND METHODS:}

\subsection{Plant Material:}

The plant material was collected in December 2015 from the local Bundelkhand Jhansi area. The plant was described by local Bundelkhand people and authenticated by the
Department of Botany, Bundelkhand University, Jhansi (U.P.) India, Dr. Gaurav Nigam (Asst. Professor). A herbarium specimen of the plant (BU/Bot./Spe./Pha./01-2016/01) was preserved in the Department of Pharmacognosy, Institute of Pharmacy for further reference.

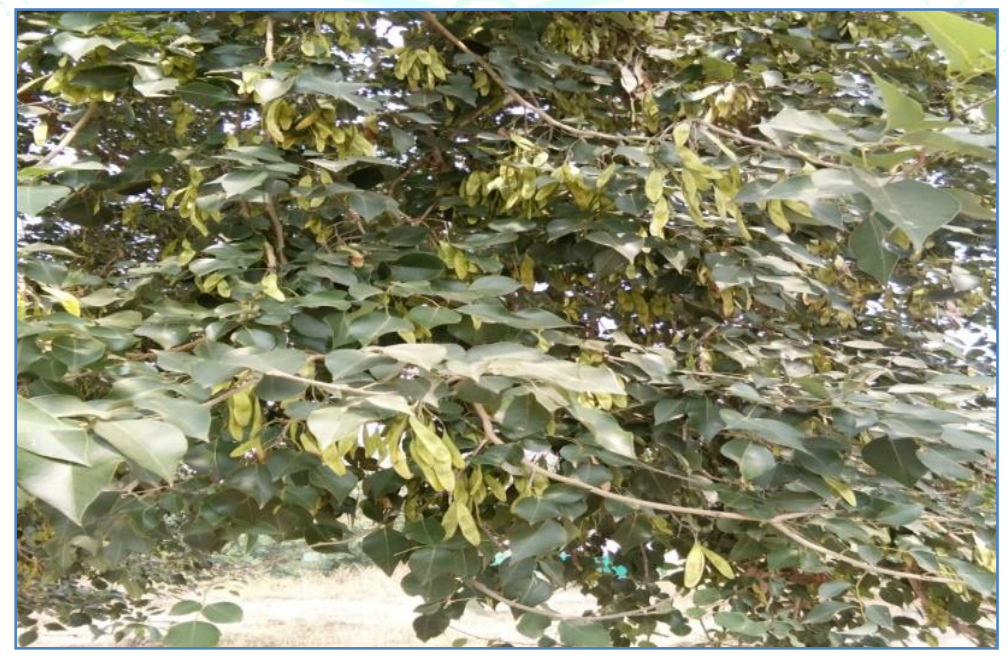

Fig. 1: Leaves of Dalbergia sissoo

\subsection{Chemicals:}

The various chemicals like ethanol, chloroform, benzene, $n$ hexane, ethyl acetate, toluene, formic acid, petroleum ether, sodium \& pot. hydroxide, sulphuric acid, hydrochloric acid, nitric acid, glacial acetic acid, iodine silica gel 60-80 mesh and Silica gel 60 F254 precoated Aluminium plates $0.2 \mathrm{~mm}$ are used.

\subsection{Extraction of Plant Materials:}

For continuous hot extraction with petroleum ether and ethanol, a total of $250 \mathrm{~g}$ coarse powder of air dried Dalbergia sissoo leaves is packed in muslin cloth and subjected to soxhlet extractor for $8 \mathrm{~h}$ separately. Then the individual extracts are filtered and purified to dryness.

\subsection{Fourier Transform Infrared (FTIR) Spectroscopy:}

As infrared light passes through a sample of an organic compound, some of the frequencies will be absorbed; however, other frequencies will be transmitted through the sample without absorption. Infrared absorption is related to the vibrational changes that occur when exposed to infrared radiation within a molecule. Infrared spectroscopy can therefore be defined basically as a vibrational spectroscopy. Different bonds $(\mathrm{C}-\mathrm{C}, \mathrm{C}=\mathrm{C}, \mathrm{C}-\mathrm{O}, \mathrm{C}=\mathrm{O}, \mathrm{O}-\mathrm{H}$, and $\mathrm{N}-\mathrm{H})$ have diverse vibrational frequencies. If these types of bonds are present in an organic molecule, the characteristic frequency absorption band in the infrared spectrum can be observed 11. Fourier Transform Infrared Spectroscopy (FTIR) is a high-resolution analytical tool for recognizing chemical components and clarifying structural compounds. FTIR provides a quick and non-destructive investigation into herbal extracts or powders fingerprints. 


\subsection{Nuclear Magnetic Resonance Spectroscopy (NMR):}

NMR is primarily associated with the magnetic properties of certain atomic nuclei, including the hydrogen nucleus, the proton, the nickel and the carbon isotope. NMR spectroscopy has enabled many researchers to study molecules by recording the differences between the different magnetic nuclei, giving a clear picture of what these nuclei's positions are in the molecule. It will also indicate that atoms are present in neighboring groups. Ultimately, it can conclude how many atoms are present in each of these environments 12. In the past, several attempts have been made to isolate individual phenols using preparatory or semi-preparative thin-layer chromatography, liquid chromatography, and column chromatography 13 .

\subsection{Mass Spectrometry for Chemical Compounds Identification:}

In mass spectrometry, organic molecules are bombarded with either electrons or lasers and thus converted to highly energetic charged ions. A mass spectrum is a plot of a broken ion's relative abundance against the mass / charge ratio of these ions. The relative molecular mass (molecular weight) can be measured with high precision using mass spectrometry and an exact molecular formula can be calculated with knowledge of the positions where the molecule is broken ${ }^{14}$. Bioactive pith molecules have been isolated and purified in previous work through bioactivityguided extraction of solvents, column chromatography, and HPLC 15. UV-visible, IR, NMR, and mass spectroscopy techniques were used to characterize the bioactive molecule's structure. In addition, molecules can be hydrolyzed, characterizing their derivatives.
Mass spectrometry provides ample data when applying tandem mass spectrometry (MS) to structural elucidation of compounds. The combination of HPLC and MS therefore facilitates the rapid and accurate identification of chemical compounds in medicinal herbs, particularly where there is no pure standard ${ }^{16}$. LC / MS has recently been commonly used for phenolic compound analysis.

\section{RESULTS AND DISCUSSION}

\subsection{Extraction of Plant Materials:}

The percentage yield of the extracts of petroleum ether and ethanol is shown in Table 2 below.

\section{Table 2: Extraction of Plant Materials}

\begin{tabular}{clll}
\hline S. NO. & Solvent & Wieght of drug (g) & \% yield \\
\hline $\mathbf{1}$ & Pt. Ether (80\%) & 250 & 3.342 \\
\hline $\mathbf{2}$ & Ethanol (100\%) & 250 & 8.198 \\
\hline
\end{tabular}

\subsection{Infra Red Spectroscopy}

IR radiation generally refers to that portion of the electromagnetic spectrum between the microwave and visible region.

Near IR= 0.8 to $2.5 \mu$ or $12500-4000 \mathrm{~cm}^{-1}$

IR Region $=2.5$ to $15 \mu$ or $4000-667 \mathrm{~cm}^{-1}$

Far IR= 15 to $200 \mu$ or $667-50 \mathrm{~cm}^{-1}$

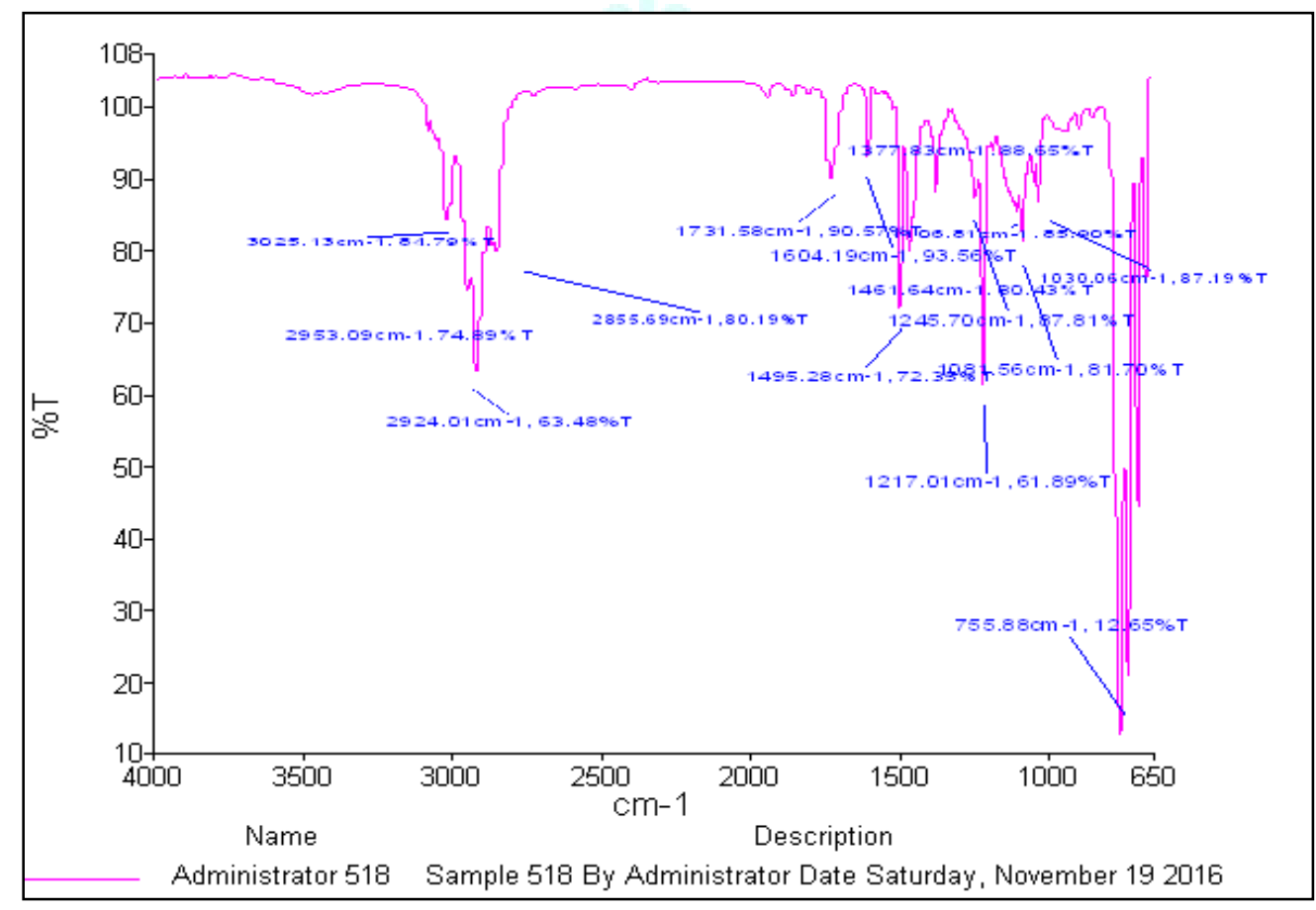

Figure 2: IR Spectra of Isolated Compound from Ethanolic Extract of Dalbergia sissoo Linn. 
Table 3: Interpretation of IR Spectra of Isolated Compound

\begin{tabular}{|c|c|c|c|}
\hline S. No. & Wave Number $\left(\mathrm{cm}^{-1}\right)$ & Functional Group & Assignment \\
\hline 1 & 3025.13 & - & Ar-H Stretching \\
\hline \multirow[t]{3}{*}{2} & 2953.09, & - & Aliphatic CH Stretching \\
\hline & 2924.01 and & & (Symmetry and Asymmetry) \\
\hline & 2855.69 & & \\
\hline \multirow[t]{3}{*}{3} & & 0 & $\mathrm{C}=0$ Stretching \\
\hline & 1731.58 & $\|$ & \\
\hline & & ---C--- & \\
\hline 4 & 1604.19 & Di-enes & $\mathrm{C}=\mathrm{C}$ Stretching \\
\hline 5 & 755.88 & $\begin{array}{l}\text { Nononeuclear aromatic benzene } \\
\text { monsubtituted }\end{array}$ & $\mathrm{C}-\mathrm{H}$ out of plane \\
\hline
\end{tabular}

\subsection{Nuclear Magnetic Resonance (NMR) Spectroscopy-}

NMR's most significant use is in the study of organic molecules ' hydrogen atoms. C-NMR isolated compound spectra from Dalbergia sissoo Linn ethanolic extract shown in figure 3.

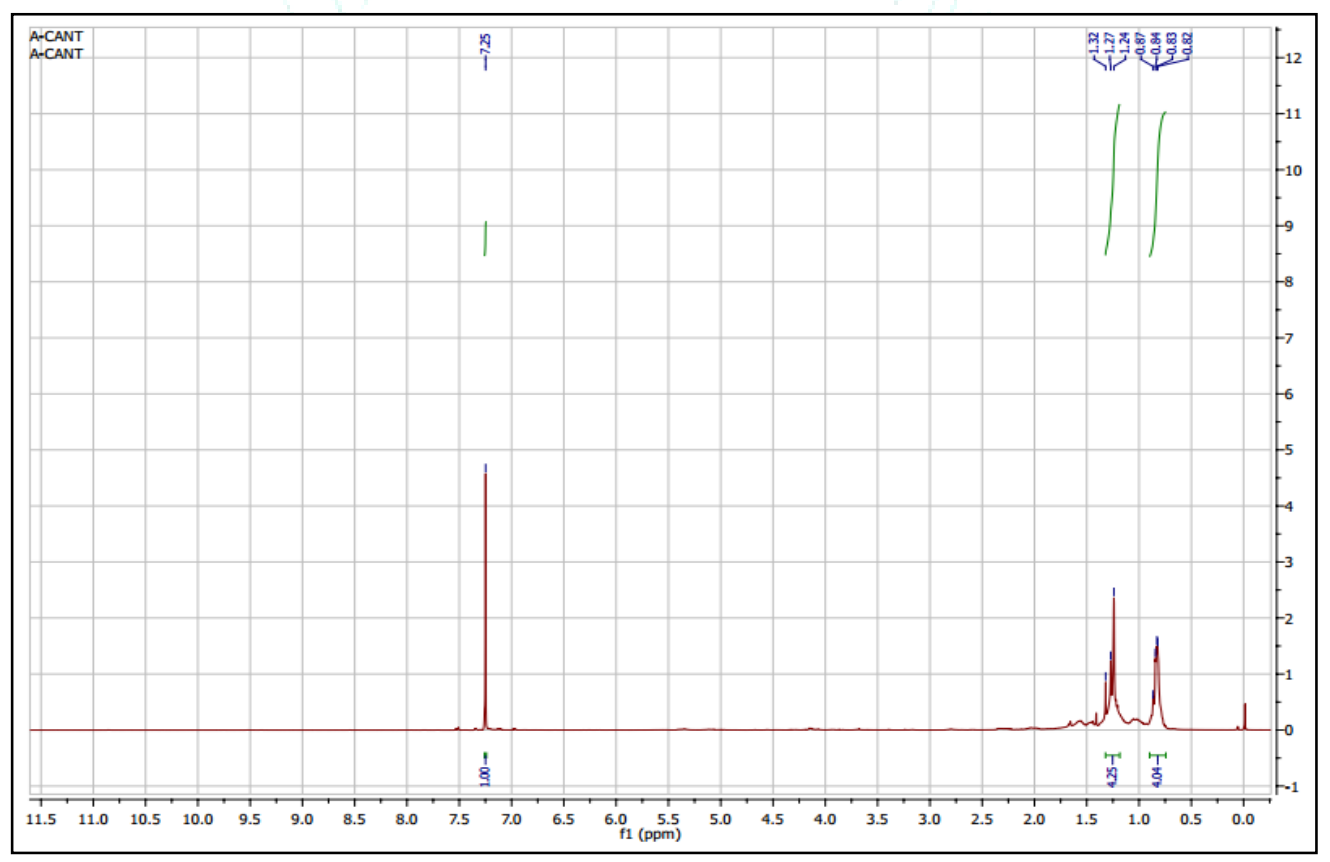

Figure 3: C-NMR Spectra of Isolated Compound from Ethanolic Extract of Dalbergia sissoo Linn

Table 4: Interpretation of NMR Spectra of Isolated

\begin{tabular}{cccccc}
\hline S. No. & $\boldsymbol{\delta}$ value ( in ppm ) & Assignment \\
\hline 1 & 7.25 & & \\
2 & 1.3 & $-\mathrm{CH}_{-}$ \\
3 & 0.7 & $-\mathrm{CH}_{3}$ \\
\hline
\end{tabular}




\subsection{Mass spectroscopy:}

The graph of $\mathrm{m} / \mathrm{e}$ values along the abscissa and their relative intensities along the ordinate is called the continuum of masses. C-NMR isolated compound spectra from Dalbergiasissoo Linn ethanolic extract shown in figure 10.

$$
\mathrm{M}^{+}(\mathrm{g}) \rightarrow \mathrm{M}_{1}{ }^{+} \mathrm{M}_{2}
$$

$$
\mathrm{M}_{1}+\mathrm{M}_{2}{ }^{+}
$$

\subsubsection{Interpretation of mass spectra of isolated} compound:

The mass fragments comes at $\mathrm{m} / \mathrm{z} 218.06,290.12,410.17$ and 664.19 following are the proposed structure that fragmentation pattern.

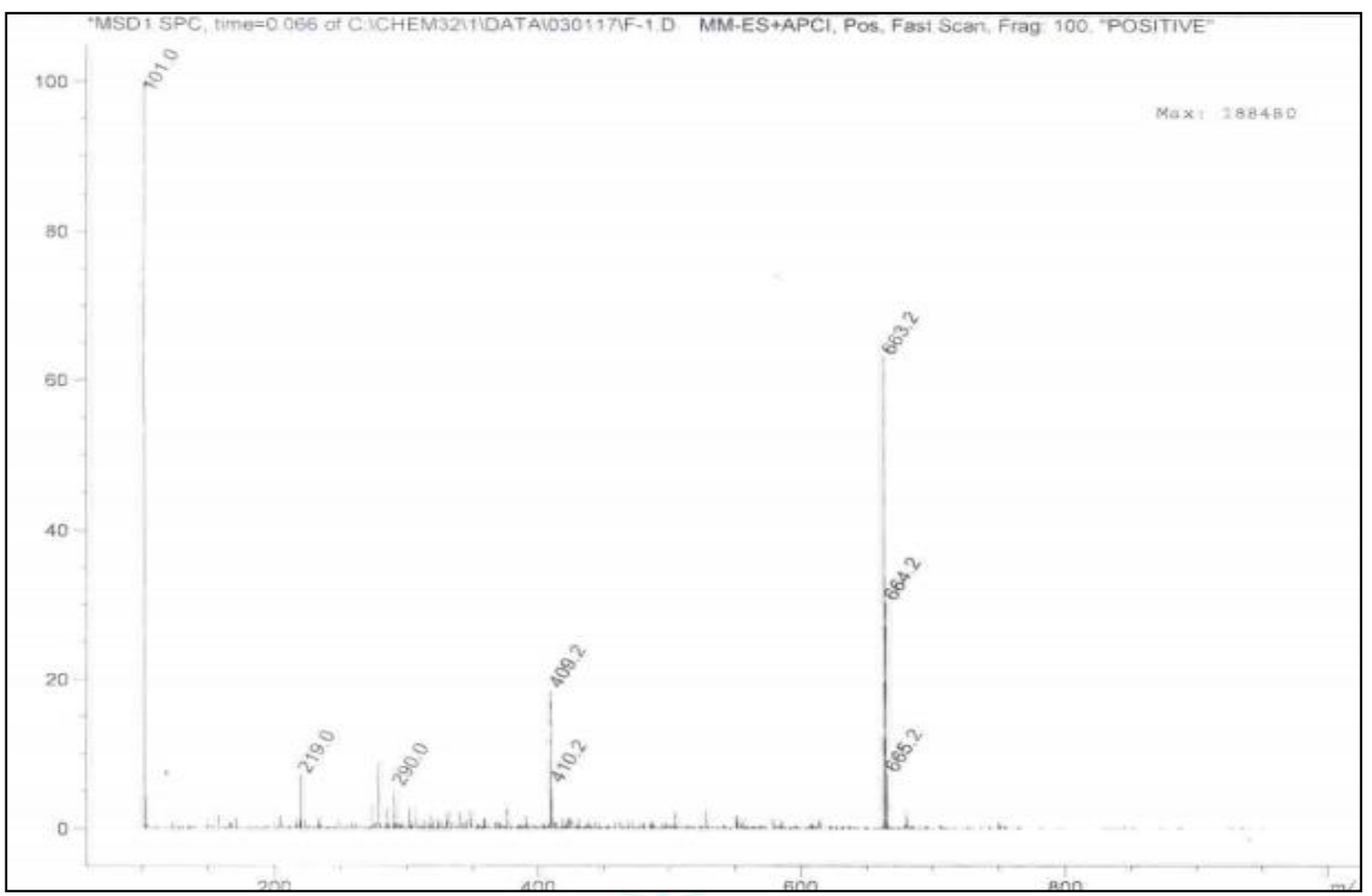

Figure 4: Mass Spectra of Isolated Compound from Ethanolic Extract of Dalbergia sissoo Linn.

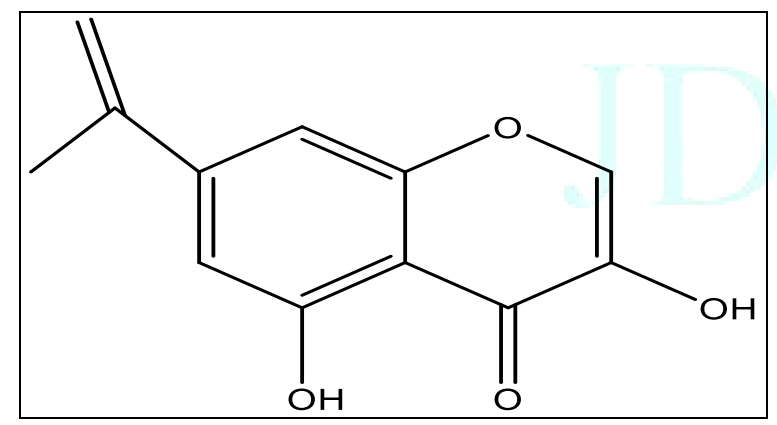

Chemical Formula: $\mathrm{C}_{12} \mathrm{H}_{10} \mathrm{O}_{4} \quad$ Exact Mass: 218.06

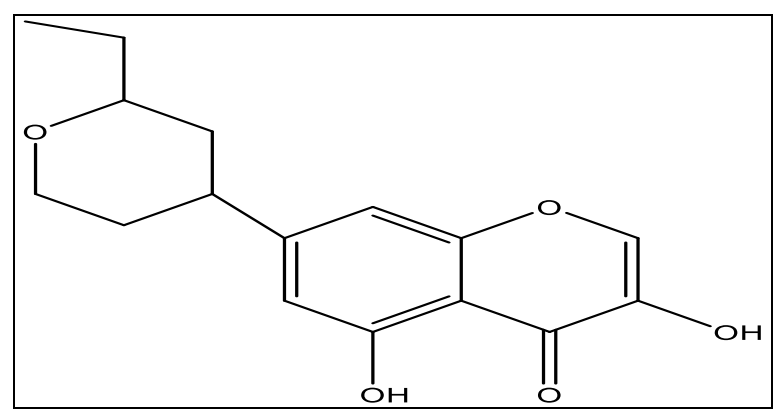

Chemical Formula: $\mathrm{C}_{16} \mathrm{H}_{18} \mathrm{O}_{5} \quad$ Exact Mass: 290.12

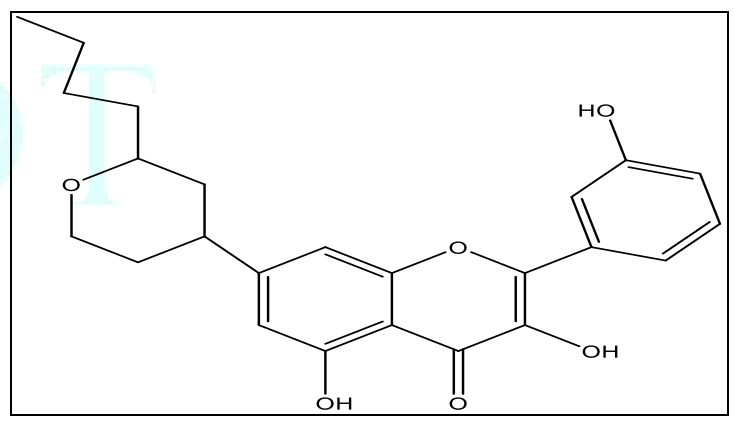

Chemical Formula: $\mathrm{C}_{24} \mathrm{H}_{26} \mathrm{O}_{6} \quad$ Exact Mass: 410.17

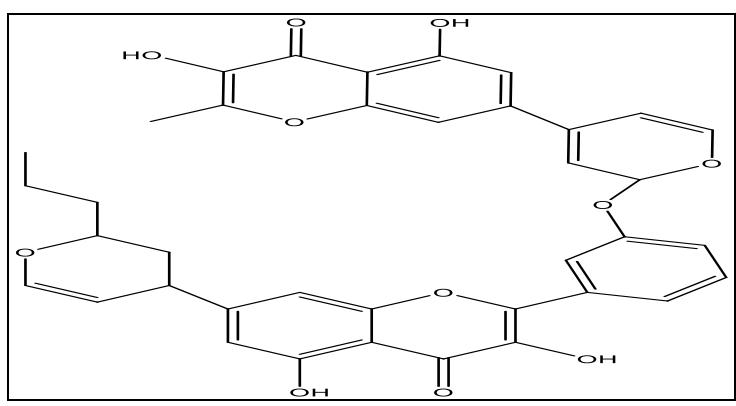

Chemical Formula: $\mathrm{C}_{38} \mathrm{H}_{32} \mathrm{O}_{11}$ Exact Mass: 664.19

Figure 5: Different Fragments of Isolated Compound from Ethanolic Extract of Dalbergia sissoo Linn. 


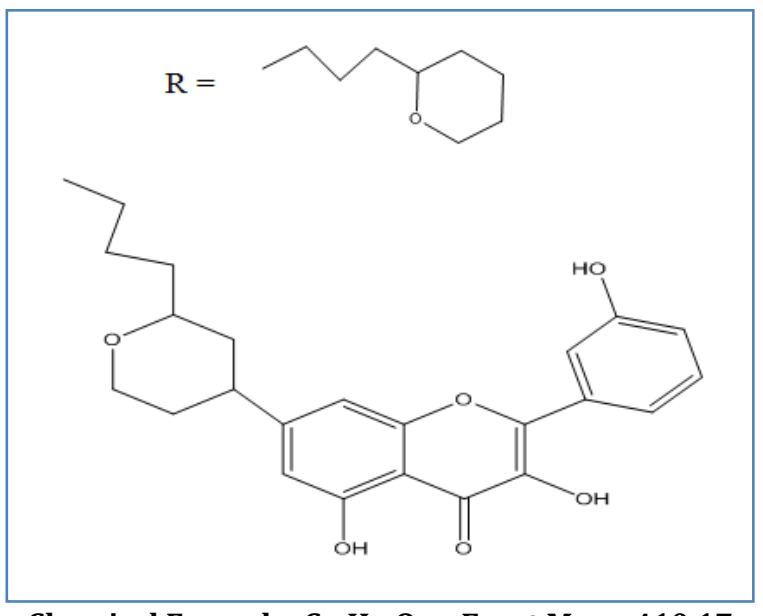

Chemical Formula: $\mathrm{C}_{24} \mathrm{H}_{26} \mathrm{O}_{6} \quad$ Exact Mass: 410.17

Figure 6: Flavanoid Derivative Having Quercetin Like Structure $\left(\mathrm{R}=\mathrm{C}_{9} \mathrm{H}_{18} \mathrm{O}\right)$

\section{CONCLUSION:}

On the basis of IR, NMR, Mass spectroscopy and elemental analysis of isolated compound the structure which may be possible is Flavanoid derivative having Quercetin like structure $\left(\mathrm{R}=\mathrm{C}_{9} \mathrm{H}_{18} \mathrm{O}\right)$.The molecular formulaC $\mathrm{C}_{24} \mathrm{H}_{26} \mathrm{O}_{6}$ and molecular mass of isolated compound.

\section{ACKNOWLEDGEMENT:}

We are grateful to Dr. S.K. Jain (Associate professor) and Dr. Shashi Alok (Assistant Professor), Faculty of Pharmacy, Bundelkhand University, Jhansi for his assistance and encouragement. We extend our sincere thanks to Dr. Pushpendra Kannojia (Associate Professor and Principal), BIU College of Pharmacy, Bareilly International University, Bareilly, for critically reading the Manuscript and providing the valuable suggestions.

\section{CONFLICT OF INTEREST: Nil}

\section{REFERENCES:}

1. Akerele 0 . Medicinal plants and primary health care: an agenda for action, Fitoterapia, 1988; 59:355-363.

2. Ivanova $\mathrm{D}$, Gerova $\mathrm{D}$, Chervenkov $\mathrm{T}$ and Yankova $\mathrm{T}$ Polyphenols and antioxidant capacity of Bulgarian medicinal plants, J Ethnopharmacol, 2005; 96:145-150.
3. Shukla $\mathrm{P}$ and Mistra SP. An introduction to taxonomy of Angiosperms. Vikas Publishing HousePvt Ltd, firsted., New York, 1979; 196-205.

4. Bhattacharya M, Singh A and Ramrakhyani C. Dalbergia sissoo An Important Medical plant Journal of Medicinal Plants Studies. Journal of Medicinal Plants Studies 2014; 2(2):76-82.

5. Taha S, Abdul $M$ and Abdul G. Phytochemical and Pharmacological studies of Dalbergia sissoo growing in Egypt, Pharmaceutical Biology 1999; 37(1):54-62.

6. Niranjani PS, Singh S, Prajapati K and Jain SK, Antidiabetic activity of ethanolic extract of Dalbergiasissoo L. Leaves in Alloxan-Induced diabetic rats, International Journal of Current Pharmaceutical Research 2010; 2(2):24-27.

7. Rahman et al., Study of medicinal plants in the Graveyards of Rajshahi city, Research Journal of Agriculture and Biological Sciences 2008; 4(1):70-74.

8. Asif M and Kumar A. Anti-Inflammatory activity of ethanolic Extract of Dalbergia sissoo (Roxb.) bark, Malaysian Journal of Pharmaceutical Sciences 2009; 7(10):39-50.

9. Fatima A, Singh PP, Agarwal P, Irchhaiya R, Alok S and Verma A, Treatment of various diseases by Carissa spinarum L. A promising shrub. Int J Pharm Sci Res 2013; 4(7):2489-2495. doi: 10.13040/IJPSR. 0975-8232.4(7).2489-95.

10. Soni RK, Irchhaiya R, Dixit V and Alok S, Paederia foetida Linn: Phytochemistry, pharmacological and traditional uses. Int J Pharm Sci Res 2013; 4(12):4525-30. doi: 10.13040/IJPSR. 0975-8232.4(12).4525-30.

11. Urbano M, Luque de Castro MD, Pérez PM, García-Olmo J, Gómez-Nieto MA, Ultraviolet-visible spectroscopy and pattern recognition methods for differentiation and classification of wines. Food Chem 2006; 97:166-175.

12. Kemp W. Energy and electromagnetic spectrum. In Organic Spectroscopy; Kemp,W., Ed.; Macmillan Press:London, UK, 1991; 1-7.

13. Kemp W. Infrared spectroscopy. In Organic Spectroscopy; Macmillan Press Ltd.: London, UK, 1991; 19-56.

14. Christophoridou S, Dais P, Tseng LH, Spraul M, Separation and identification of phenolic compounds in olive oil by coupling high-performance liquid chromatography with postcolumn solid-phase extraction to nuclear magnetic resonance spectroscopy (lc-spe-nmr). J. Agric. Food Chem 2005; 53:4667-4679.

15. Cherkaoui A, Hibbs J, Emonet S, Tangomo M, Girard M, Francois P, Schrenzel J, Comparison of two matrix-assisted laser desorption ionization-time of flight mass spectrometry methods with conventional phenotypic identification for routine identification of bacteria to the species level. J. Clin. Microbiol 2010; 48:1169-1175.

16. Beckey HD 1971, 1-Theory of Field Ionization (FI) and Field Emission (FE); Pergamon: Bergama, Turkey. 